\title{
Engelli ve Engelli Adayı Bireylerin Bir Afet Anında Nasıl Davranacaklarına İlişkin Görüşleri
}

\author{
Esma BULUŞ KIRIKKAYA ${ }^{1}$, Serpil GERDAN ${ }^{2}$
}

\section{Öz}

Beklenmedik olarak ortaya çıkan ve toplulukları olumsuz etkileyen doğal veya insan kökenli tehlikelerin topluluklar üzerindeki sonuçları afet olarak nitelendirilmektedir. Tüm dünyada olduğu gibi ülkemizde de gerek doğal kaynaklı gerekse teknolojinin veya insan faktörünün bilerek veya bilmeyerek sebep olduğu tehlikelerin sonucu olarak yaşam alanlarımız afetlere maruz kalmakta ve insanlar mağdur olmaktadır. Bu afetler sonucunda can ve mal kayıpları olmakta ve insanların yaşamlarındaki bu değişimler travmalara neden olmaktadır. Kaynağı doğadan gelen tehlikelerin meydana gelmesi çoğu zaman engellenememekle birlikte birey/toplumlara vereceği hasarlar/kayıplar en aza indirgenebilir. Bunu sağlayabilmenin en önemli yollarından biri toplumu meydana getiren her birey için güvenli bir çevrenin oluşturulmasıdır. Bu çalışmada, Kocaeli Üniversitesi Eğitim Fakültesi öğrencilerinin Topluma Hizmet Uygulamaları dersi kapsamında Kocaeli İli, İzmit ilçesindeki engelli birey, engelli adayı birey ve öğretmenler üzerinde "Engellilerin Kentsel Alanda Karşılaştıkları Sorunlar" konulu çalışmanın afet boyutunda değerlendirilmesine ait sonuçlar yer almaktadır. Çalışma, 30 engelli birey, 50 engelli adayı birey ve 25 öğretmen ile yarı yapılandırılmış görüşme yapılarak gerçekleştirilmiştir ve bir afet durumunda nasıl davranılacağı konusunda farkındalık düzeyinin belirlenmesini içermektedir. Çalışmanın çarpıcı sonuçlarından bazıları; engellilerin afet anında doğrudan kaçmayı düşündüklerini, öğretmenlerin engelli öğrencilere afetlerle ilgili davranış şekillerini öğretmeye gönüllü olduklarını gösterirken engelli adayı bireylerin ise afet anında önceliği engelli yakınına vermeye eğilimli olduklarını göstermektedir.

Anahtar Sözcükler: Afet, Engelli birey, Afet eğitimi.

\section{Opinions of Disabled and Disabled Candidate Individuals about how They Behave at a Disaster}

\begin{abstract}
Unexpected natural and technological dangers and the result of dangers on communities are defined as disasters. Inourcountry as well as allover the world, the result of the factors both natural and technology origin as our habitats are exposed to disasters and people are victims. These disasters result in loss of life and property, and these changes in people's lives cause trauma. Although the dangers that comes from nature mostly cannot be prevented, the damage / losses to the individual / society can be minimized. One of the most important ways to achieve is to create a safe environment for every individual who makes society. This study includes the results of disaster assessment that is part of the study of students of Kocaeli University Education Faculty in the scope of Community Service Practices in İmit district of Kocaeli disabled individual, disabled candidate and teachers on the "Disabilities in the Urban Area Problems encountered". The study was realised 30 people with disabilities, 50 people with candidate disabilities and 25 teachers. Some of the interesting results of the study; the people with disabilities are considering to escape directly in disasters, teachers are willing to teach disabled students behaviors related to disasters and also disabled candidates are abilities are prone to give priority to disabled relatives at the time of disaster.
\end{abstract}

Keywords: Disaster, Disability individual, Disaster education.

\footnotetext{
${ }^{1}$ Kocaeli Üniversitesi, Eğitim Fakültesi, Matematik ve Fen Bilimleri Eğitimi Bölümü, İzmit, Kocaeli, Türkiye

2 Kocaeli Üniversitesi, İzmit Meslek Yüksekokulu, İzmit, Kocaeli, Türkiye

İlgili yazar / Corresponding author: bulus@kocaeli.edu.tr

Gönderim Tarihi: 02.11.2018

Kabul Tarihi: 27.12.2018
}

Bu makaleye atıf yapmak için- To cite this article Buluş Kırıkkaya, E., \& Gerdan, S. (2018). Engelli ve Engelli Adayı Bireylerin Bir Afet Anında Nasıl Davranacaklarına Illişkin Görüşleri. Resilience, 123-129. 


\section{Giriş}

Engellilik kavramının ortak bir tanımı olmamakla birlikte yaygın olarak "Bedensel, zihinsel ve ruhsal özelliklerinde belirli oranda fonksiyon kaybına neden olan organ yokluğu ve bozukluğu sonucu, toplumsal rolünü gerçekleştirebilmesi için bakım, rehabilitasyon, danışmanlık ve destek hizmetlerine intiyaç duyan kişi" olarak tanımlanmaktadır (Yiğit ve diğ; 2009). Ülkemizde tüm dünyada olduğu gibi engelliler toplumun önemli bir kesimini oluşturmaktadır. Ülkemiz nüfusunun yaklaşık \%12'si engelli bireylerden oluşmaktadır (Yumuşak, 2014).

Afetler normal düzeni bozan ve meydana geldiklerinde karmaşaya sebep olan olaylardır. Günümüzde artık afetler, olayların kendisinden çok hazırlıksız toplumların yüzleşmek zorunda oldukları sonuçlar olarak ifade edilmektedir. Afetler her ne kadar kökenleri bakımında doğal ve teknolojik (insan) kaynaklı olarak sınıflandırılsa da kentsel alanlarda afet denince deprem, sel gibi doğa olaylarının sebep olduğu felaketler algılanmaktadır. Çoğu toplumda tehlikenin kökeninin doğa olması ve doğaya karşı koymanın zor hatta imkansız olarak algılanması bireyleri veya toplulukları çaresizliğe itmektedir. Bu durum o toplumun zarar görebilirliğini artıran en önemli faktörlerden biridir. Hızlı ve denetimsiz yapılaşma, sanayileşme, hızlı nüfus artışı, bilgi ve eğitim eksikliği zarar görebilirliğin nedenleri arasında ön sıralarda yer almaktadır. Buna bireyin ve toplumun afetlerle mücadele kapasitesinin yetersizliği ve bilgisizlik te eklendiğinde afete karşı savunmasız, kırılgan toplumlar ortaya çıkmaktadır (Ergünay, 2009). Afetlerde ve toplumsal kriz durumlarında toplumun etkilenme biçimi, şiddeti ve etkiye verebildikleri yanıtlar farklı olmakla birlikte özellikle başta doğal afetler olmak üzere hangi tür olay olursa olsun en fazla etkilenecek dezavantajlı gruplar engelliler ve yaşlılardır ve bu nedenle yapılacak afete hazırlık çalışmaları engelli bireyler göz önüne alınarak planlanmalıdır (Saygılı, 2011; URL-1). Afetler karşısında risk grupları değerlendirildiğinde, engelliler, daha heterojen bir grup olarak düşünülebilir. Engelli ya da dezavantajı grup olarak nitelediğimiz bu grup aslında çok farklı intiyaç ve kapasiteler sahip, fiziksel, duyusal ya da zihinsel yeti yitim veya bozukluğa sahip bireylerdir ve bu bireyler toplumsal engellerle karşılaştıklarında diğer bireylerle eşit, tam ve etkili katılımını gerçekleştiremez durumdadırlar. Toplumun ve kentsel alanların onlara sunduğu bu olumsuzluklar afet durumunda daha etkin çözümlerin geliştirilebilmesi zorunlu kılmaktadır (URL-2; URL-3). Çoğu zaman afet sonrası nüfusun en az beşte biri afetten önceki durumdan daha zor durumda yaşamaya başlamakta, afet sonrası ortaya çıkan kaosta yaşam rutinleri kesintiye uğradığı için zarar görmektedir. Engelliler de, çoğu zaman toplum geneline kıyasla daha kötü yaşam koşullarına sahip olmaları nedeniyle daha zor durumda kalmaktadırlar. Diğer taraftan arama kurtarma faaliyetleri de genellikle daha geniş kategorileri düşünmektedir. Afet anında veya sonrasında engelli bireye yardım etmek onun intiyaçlarına uygun özel yöntem ve hazırlıklar gerektirmektedir. Bir afet durumunda, engelli bireylerin diğer bireylerden daha fazla zorlukla karşı karşıya kalacağı düşünüldüğünde engellilerin günlük yaşam, kurtarılma, sığınak vb. konularda yaşadıkları bu gibi zorlukların acil durum planlamalarında göz önünde bulundurulması gerektiği unutulmaması gereken önemli konulardan biridir (Özbayram, 2018; URL-4).

\section{Yöntem}

Olası tehlikeler yaşanan coğrafyaya göre değişiklik göstermekle birlikte ortaya çıkacak olumsuz sonuçları açısından son derece önemli bir konudur. Kentsel yaşamın karmaşası içerisinde çok fazla aklımıza gelmeyen doğal tehlikeler çoğu zaman yıkıcı etkilere sahiptir ve insan-mekân etkileşiminde dikkat edilmesi gereken unsurlardan biridir (Karakuş ve Önger, 2017). Bireylerin afet öncesi, sırası ve sonrası neler yapmaları gerektiği konusunda bilgi ve eğitimli olmaları, ülkemiz gibi sıklıkla afetlere maruz toplumlar için, oldukça önemlidir. Bu çalışmada Kocaeli Üniversitesi, Eğitim Fakültesinde eğitimlerine devam eden öğretmen adaylarının Topluma Hizmet Uygulamaları dersi kapsamında engelli, engelli adayı ve 
öğretmenlerin afetlerdeki davranış biçimlerinin ne olacağı araştırılmıştır. Bu kapsamda; 30 engelli birey, 50 engelli adayı birey ve 25 öğretmene "Bir afet durumunda (deprem, sel ya da bir terör olayı) nasıl davranacağınızı hiç düşündünüz mü? (nasıl davranırsınız)", "Bir afet anında engelli biriyle olsanız ne yapardınız?", "Bir afet anında engelli öğrencinizin ne yapması gerektiğini düşündünüz mü?" sorularına cevap aranmıştır.

Çalışma, nitel araştırma yöntemlerinden olgubilim yöntemine göre desenlenmiştir. Olgubilim deseni farkında olduğumuz ancak derinlemesine ve ayrıntılı bir anlayışa sahip olmadığımız olgulara odaklanmaktadır (Yıldırım ve Şimşek, 2006).

$\mathrm{Bu}$ çalışmanın verileri yarı yapılandırımış görüşmelerden elde edilmiştir. Bunun için görüşmeler öncesi bir görüşme formu hazırlanmıştır. Sorular hazırlanırken literatür taranmış ve engelli, engelli adayı/yakını ve öğretmenler için olmak üzere üç farklı form düzenlenmiştir. Formdaki görüşme sorularının yanıtlanabilir olma durumu üç farklı kesim için de deneme yapılarak kontrol edilmiştir.

Çalışma grubunun belirlenmesinde doğal ve teknolojik tehlikelere maruz konumda olan ve 1999 depremlerini yaşamış bir yer olan Kocaeli ili İzmit merkez ilçesi seçilmiştir. Özellikle engelli bireylerin kendileriyle anket ya da görüşme yapılmasında istekli olmamaları nedeniyle çalışmaya sadece görüşmeyi kabul eden bireyler dahil edilebilmiştir. Gerek engelli gerekse engelli adayı bireylere rasgele ulaşıımıştır. Araştırmanın veri toplama aşaması, 2017-2018 Eğitim Öğretim Bahar yarıyılında yapılmıştır. Katılımcılara ait bilgiler Tablo 1, Tablo 2 ve Tablo 3'de verilmektedir.

Tablo 1. Engelli katılımcılara ait bilgiler

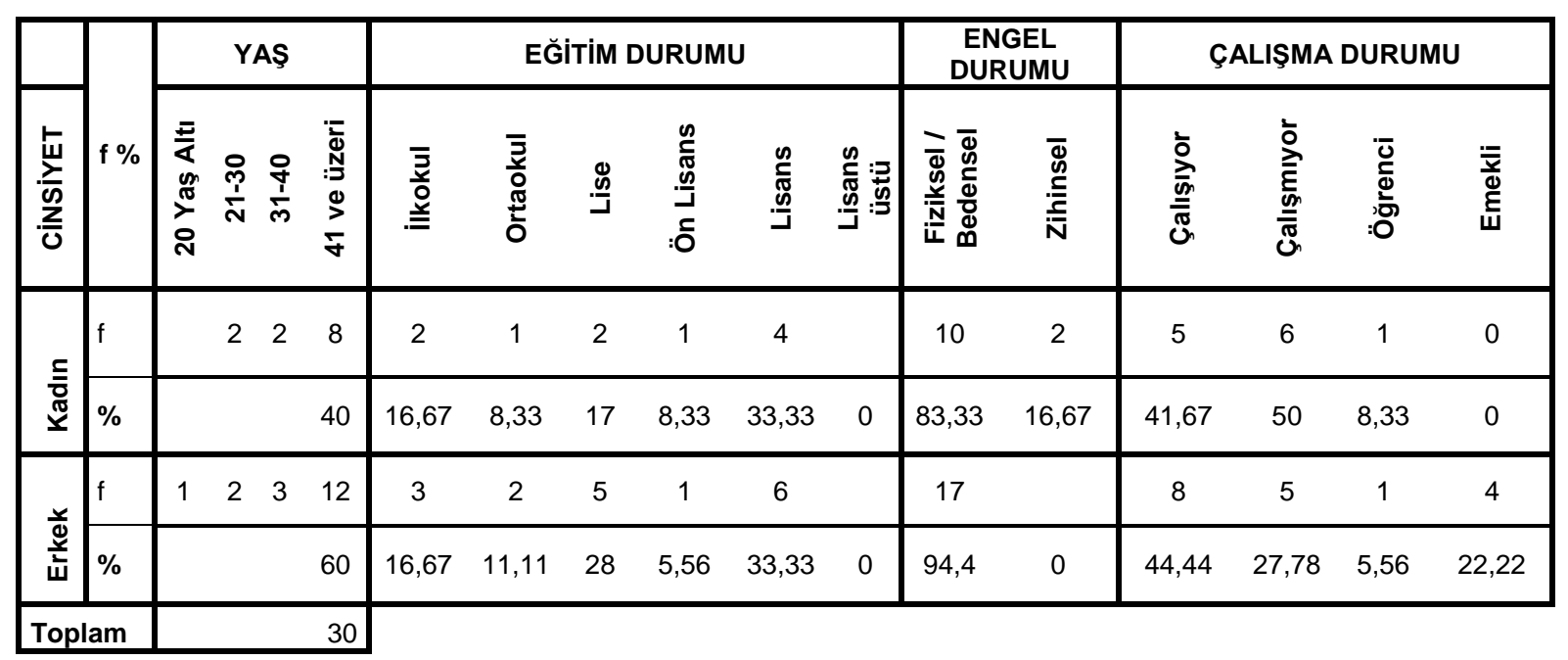

Araştırmaya katılan engelli bireylerin \%40'ını kadınlar, \%60'ını erkekler oluşturmaktadır. Engelli kadın katılımcıların \%33,33'ü lisans mezunu iken, \%8,33'ü ön lisans ve \%17'si lise mezunudur. Kadın katılımcıların \%83,33'ü fiziksel/bedensel engelli iken, erkek engelli katılımcıların \%94,44'ü fiziksel/bedensel engellidir. 
Tablo 2. Engelli adayı katılımcılara ait bilgiler

\begin{tabular}{|c|c|c|c|c|c|c|c|c|c|c|c|c|c|c|c|}
\hline \multirow[b]{2}{*}{ 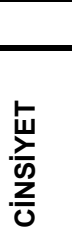 } & \multirow[b]{2}{*}{$f \%$} & \multicolumn{4}{|c|}{ YAŞ } & \multicolumn{6}{|c|}{ EĞіTIM DURUMU } & \multicolumn{4}{|c|}{ ÇALIŞMA DURUMU } \\
\hline & & $\begin{array}{l}\frac{\pi}{\alpha} \\
\text { m } \\
\frac{\pi}{2} \\
\text { N }\end{array}$ & 弚 & $\underset{\substack{+ \\
\text { m }}}{-1}$ & 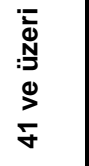 & $\begin{array}{l}\overline{\bar{z}} \\
\underline{\underline{o}} \\
\stackrel{\underline{\equiv}}{=}\end{array}$ & 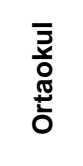 & .ֶ๊ & 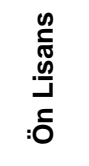 & & 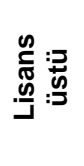 & $\frac{\grave{\grave{d}}}{\stackrel{\grave{m}}{\bar{\omega}}}$ & 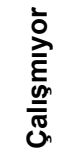 & 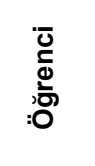 & 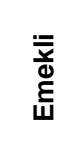 \\
\hline \multirow{2}{*}{$\overline{\bar{\varpi}}=$} & $f$ & 4 & 13 & 4 & 9 & 2 & 3 & 9 & 1 & 14 & 1 & 11 & 9 & 9 & 1 \\
\hline & $\%$ & & & & 60 & 6,67 & 10 & 30 & 3,33 & 46,67 & 3,33 & 36,67 & 30 & 30 & 3,33 \\
\hline \multirow{2}{*}{$\begin{array}{l}\frac{r}{d} \\
\frac{\grave{L}}{\dot{W}}\end{array}$} & $f$ & 1 & 9 & 2 & 8 & 1 & 2 & 7 & 4 & 9 & & 13 & 0 & 2 & 4 \\
\hline & $\%$ & & & & 40 & 5,00 & 10,00 & 35,00 & 20,00 & 45,00 & 0,00 & 65,00 & 0,00 & 10,00 & 20,00 \\
\hline \multicolumn{2}{|c|}{ Toplam } & & & & 50 & & & & & & & & & & \\
\hline
\end{tabular}

Engelli adayı katılımcıların \%60'ı kadınlardan, \%40'ı ise erkeklerden oluşmaktadır. Erkek engelli adayı katılımcıların \%45'i lisans mezunu, kadın katılımcıların ise \%45'i lisans mezunudur. Engelli erkek adaylarının \%65'i, kadın engelli adayların ise \%36,66'sı çalışmaktadır.

Tablo 3. Öğretmen katılımcılara ait bilgiler

\begin{tabular}{|c|c|c|c|c|c|c|c|c|c|c|c|c|c|}
\hline \multirow[b]{2}{*}{$\frac{\stackrel{5}{w}}{\frac{5}{0}}$} & \multirow[b]{2}{*}{ f \% } & \multicolumn{4}{|c|}{ YAŞ } & \multicolumn{2}{|c|}{$\begin{array}{c}\text { EĞITIMM } \\
\text { DURUMU }\end{array}$} & \multicolumn{6}{|c|}{ ÇALIŞMA DURUMU } \\
\hline & & $\begin{array}{l}\frac{\pi}{\alpha} \\
\text { om } \\
\frac{\pi}{2} \\
0\end{array}$ & $\begin{array}{l}\text { Pे } \\
\text { N }\end{array}$ & $\begin{array}{c}\stackrel{q}{q} \\
\vdots \\
-m\end{array}$ & 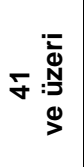 & 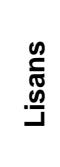 & 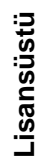 & $\frac{\vdots \bar{y}}{: 0}$ & 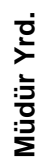 & 离 & 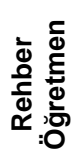 & 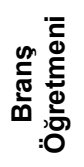 & 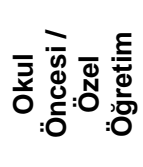 \\
\hline \multirow{2}{*}{ 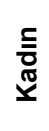 } & $f$ & & 10 & 8 & 2 & 17 & 3 & & & 3 & 2 & 13 & 2 \\
\hline & $\%$ & & & & 80 & 85 & 15 & 0 & 0 & 15 & 10 & 65 & 10 \\
\hline \multirow{2}{*}{ 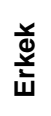 } & $f$ & & & 2 & 3 & 4 & 1 & 1 & 1 & & & 3 & \\
\hline & $\%$ & & & & 20 & 80 & 20 & 20 & 20 & 0 & 0 & 60 & 0 \\
\hline \multicolumn{2}{|c|}{ Toplam } & & & & 25 & & & & & & & & \\
\hline
\end{tabular}

Öğretmen katıımcıların \%80'inin kadın öğretmenler oluşturmaktadır. Erkek öğretmenlerin \%40'ı idareci olarak görev yapmaktadır.

Olgubilim araştırmalarında veri analizi yaşantıları ve anlamları ortaya çıkarmaya yöneliktir. Bu amaçla veri analizi içerik analizi ile gerçekleştirilir, sonuçlar betimsel bir anlatımla sunulur ve sık sık doğrudan alıntılara yer verilir (Yıldırım ve Şimşek, 2006). Bu nedenle çalışmada elde edilen verilerin analizinde içerik analizi kullanılmıştır. Analizlerden elde edilen ifadelerin sıklıkları, frekans ve yüzde olarak tablolaştııılmıştır. Ayrıca engelli, engelli adayı ve öğretmenlerin verdikleri cevaplardan doğrudan alıntılar yapılmıştır.

\section{Bulgular}

Bu bölümde araştırmadan elde edilen bulgulara yer verilmiştir. Engelliler, engelli adayları ve öğretmenlerin afetlerdeki davranış biçimlerine yönelik vermiş oldukları cevaplar tablolaştırılarak bir araya toplanmıştır. 


\subsection{Engellilerin afet anındaki davranışları}

Engelli katılımcılara bir afet anında nasıl davranmaları gerektiğini daha önce düşünüp düşünmedikleri ve "Bir afet anında nasıl davranacağınızı biliyor musunuz?" soruları yöneltilmiş ve verdikleri cevaplar Tablo 4'de özetlenmiştir.

Tablo 4. Engelli katılımcıların afet anındaki davranış biçimleri

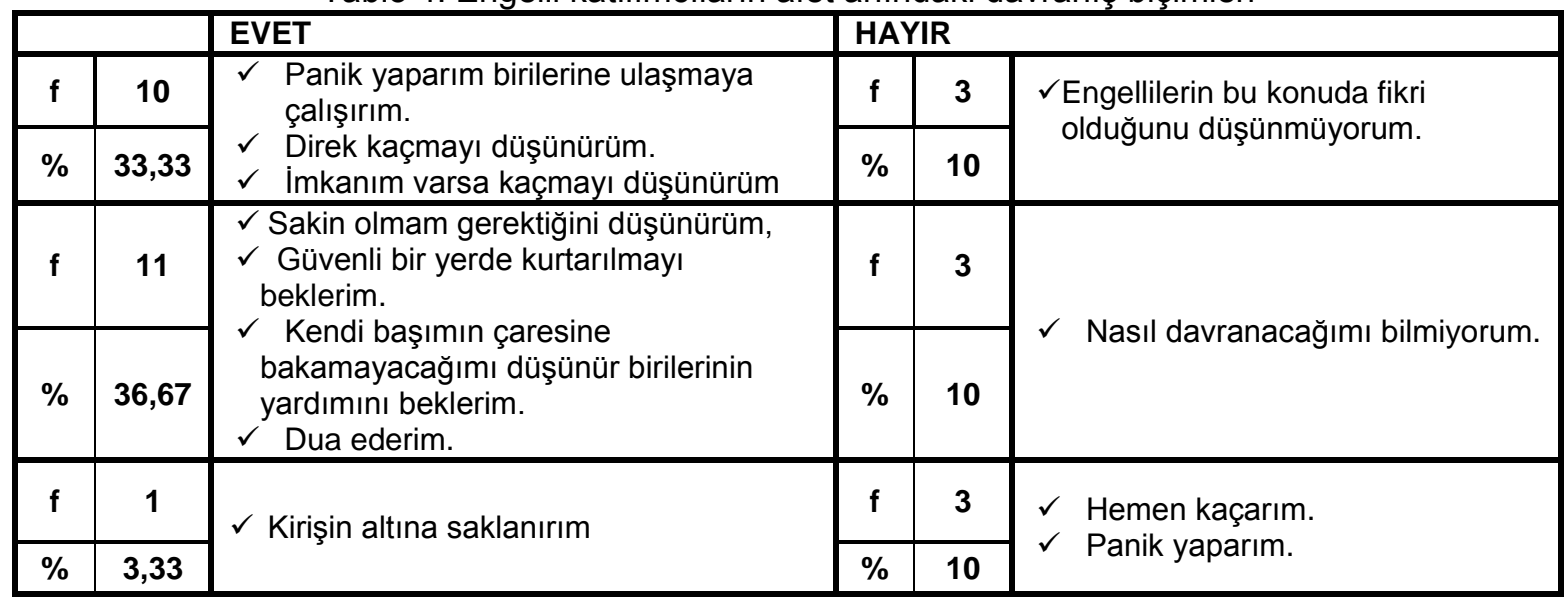

\subsection{Engelli adaylarının afet anındaki davranışları}

Engelli adayı katılımcıların "Bir afet anında nasıl davranacağınızı biliyor musunuz?" ve "Bir afet anında engelli bireylerle olsanız ne yaparsınız?" sorularına verdikleri cevaplar Tablo 5'de özetlenmiştir.

Tablo 5. Engelli adayı katılımcıların afet anındaki davranış biçimleri

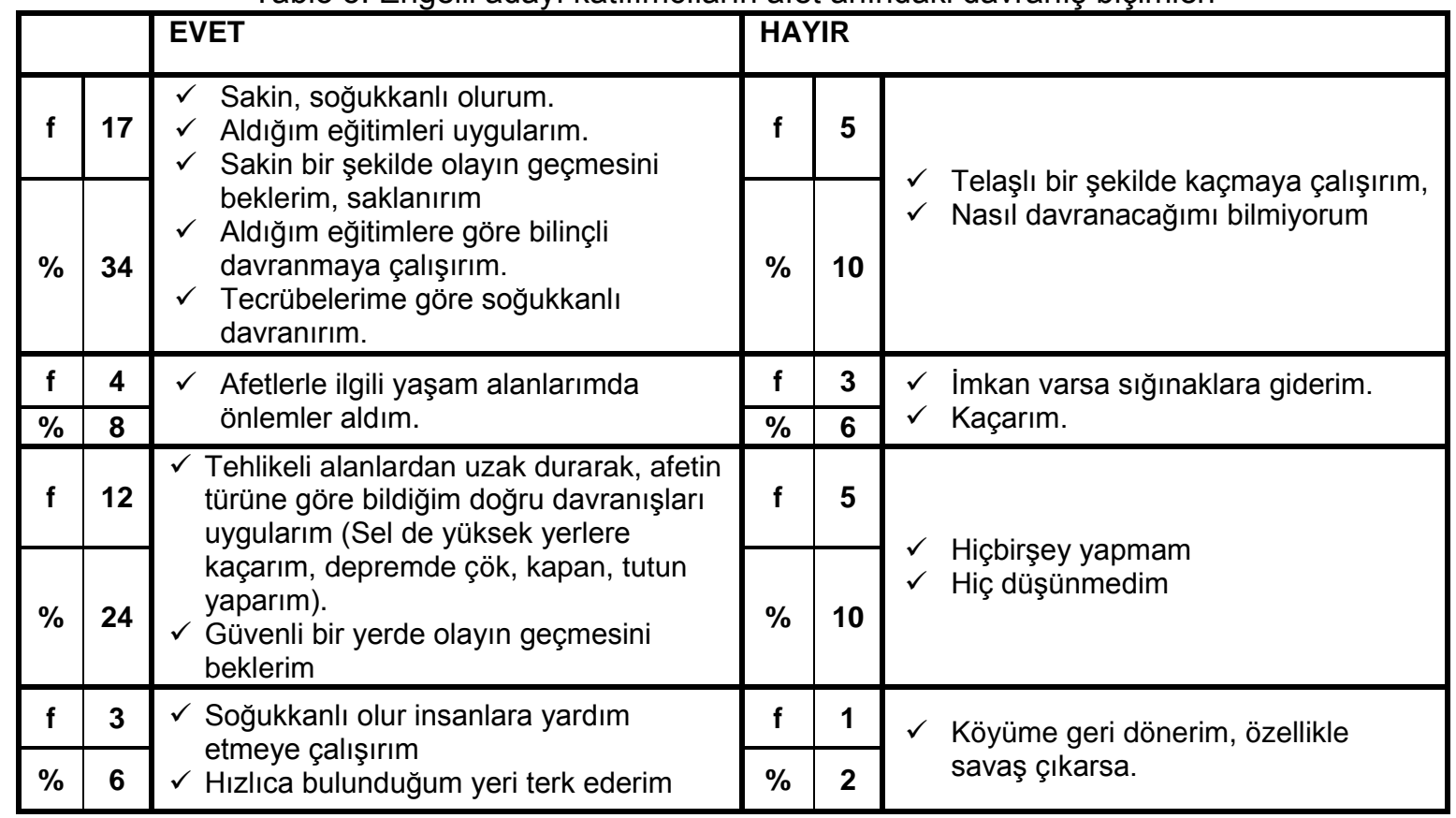

Engelli adayı katıımcıların büyük bir çoğunluğu (\%96), afet anında engelli bir yakını ya da bir bireyle olmaları durumunda engelli bireyin can güvenliğine öncelik vereceklerini ifade etmişlerdir. Sadece iki katıımcıdan biri (\%2) "bırakıp kaçarım" ve diğeri (\%2) "önce normal insanları çıkarıp, o sırada o vatandaşı sakinleştirerek güvenliğini sağlamaya çalışırım" cevabını vermiştir. 


\section{3. Öğretmen katılımcıların afet anındaki davranışları}

Öğretmen katılımcıların "Bir afet durumunda nasıl davranacağınızı hiç düşündünüz mü?" ve "Bir afet anında engelli öğrencinizin ne yapması gerektiğini düşündünüz mü? sorularına verdikleri cevaplar Tablo 6'da özetlenmiştir. Öğretmenlere ayrıca engelli öğrencilerinin olup olmadığı da sorulmuştur.

Tablo 6. Öğretmen katılımcıların afet anındaki davranış biçimleri

\begin{tabular}{|c|c|c|}
\hline$f$ & 8 & \multirow{2}{*}{$\begin{array}{ll}\checkmark & \text { Sakinliğimi korurum. } \\
\checkmark & \text { Sakin olurum, nasıl davranacağımı biliyorum }\end{array}$} \\
\hline$\%$ & 32 & \\
\hline$f$ & 5 & \multirow{2}{*}{$\checkmark$ Afetin türüne göre gerekli bilgiler edinir ona göre davranırım. } \\
\hline$\%$ & 20 & \\
\hline$f$ & 2 & \multirow[t]{2}{*}{$\checkmark$ Öğrendiğim, aldığım eğitimleri yapmaya çalışırım. } \\
\hline$\%$ & 8 & \\
\hline$f$ & 5 & \multirow{2}{*}{$\begin{array}{l}\checkmark \text { Bir fikrim yok. } \\
\checkmark \text { Düşünmedim }\end{array}$} \\
\hline$\%$ & 20 & \\
\hline
\end{tabular}

Öğretmen katılımcıların \%40'si ( $f=10$ ) bir afet anında engelli bir bireyler veya öğrenciyle olmaları durumunda güvenli bir bölgeye sığınarak, engelli adayın engel durumuna göre yardım etmeyi düşündüklerini, \%8' i $(f=2)$ engelli öğrencilerinin olması durumunda afet anıdan yapılacaklarla ilgili öğrenci ve ailesini önceden bilgilendirmenin önemli olduğunu belirtmişlerdir. 2 öğretmen (\%8) okullarda deprem tatbikatlarının yapıldığını ve bu konuda öğrencilerin gerekli bilgileri öğrendiğini söylemiştir.

\section{Sonuç ve Öneriler}

Afetler çoğu zaman beklenmedik anda gerçekleşen ve rutin yaşamı durduran veya kesintiye uğratan olaylardır. Meydana geldiklerinde toplumun her kesimini belirli ölçüde etkilemektedir. Bu olumsuz etkiler engelli veya engelli yakını olan bireylerde daha büyük sorunlara neden olmaktadır. Bu çalışma, Kocaeli Üniversitesi Eğitim Fakültesi öğrencilerinin "Topluma Hizmet Uygulamaları" dersi kapsamında Kocaeli İli, İzmit ilçesindeki engelli, engelli adayı birey ve öğretmenler üzerinde "Engellilerin Kentsel Alanda Karşılaştıkları Sorunlar" konulu araştırmanın afetlerle ilgili sonuçlarını içermektedir. Anket uygulamasındaki engelli katılımcılar gönüllülerden seçilmiştir. Toplam engelli katılımcı 30 olup; \%40'ı kadın, \%60'ı erkek katılımcıdan oluşmaktadır. Engelli adayı katılımcıların \%60'ı kadınlardan, \%40'ı ise erkeklerden oluşmaktadır. Öğretmen katıımcıların \%80'i kadın, \%20'si erkektir. Erkek öğretmenlerin \%20'si ile kadın öğretmenlerin \%15’i lisansüstü eğitim sahibidir.

$\mathrm{Bu}$ araştırmanın bulguları doğal veya teknolojik bir afetle karşı karşıya kalmış veya kalma olasılığı olan engelli, engelli adayı ve öğretmenlerin afet anında sergilemeleri gereken doğru davranış biçimleri ile ilgili bir takım sonuçları ortaya koymaktadır. Bu çalışmanın sonucuna göre katılımcıların normal şartlarda afet anındaki davranış biçimleri ile ilgili bir fikre sahip olmakla birlikte, engelli olmaları durumunda veya engelli bir yakını veya öğrencisi ile birlikte bir afete maruz kaldığının neler yapması gerektiği konusunda net bir fikre sahip olmadıklarını göstermektedir. Toplumsal yapı gereği, engelli adayı veya öğretmen katılımcıların afet anında yakınındaki engelli bireye yardım etmeye oldukça gönüllü olduğunu ve bilgi ve deneyimleri doğrultusunda biz çözüm geliştirdiklerini göstermektedir. Yapılan görüşmelerde 1999 depremlerini yaşayan bazı katılımcıların deprem anında ve öncesinde yapılması gereken doğru davranış biçimlerini bildikleri ancak bazı uygulamaların hayata geçirilmesi konusunda kaygıları olduğu görülmektedir. Bu nedenle ülke genelinde afetler konusunda verilecek eğitimlerin toplumu oluşturan tüm bireyleri kapsayacak içerikte ve nitelikte olması ve uygulamaya yönelik eğitimlerin ağırlık kazanmasının yararları unutulmamalıdır. 


\section{Teşekkür}

2017-2018 Öğretim yılı bahar döneminde Topluma Hizmet dersini alan ve bu araştırmada veri toplayarak katkıda bulunan öğrencilerimize teşekkür ederiz.

\section{Kaynaklar}

Ergünay, O., (2009), Afet Yönetimi; Genel İlkeler, Tanımlar, Kavramlar, Afet Işleri Genel Müdürlügü, Ankara

Saygıı, S. (2011). "Yaşlı Kimdir?”. Somuncu Baba Dergisi, Sayı 134, 67-68.

Özgür, Y., Yaşar, S., Tayfur, T., (200), Engelli Bireylerin Toplumsal Hayatta Yaşadıkları Zorluklar Ve Engelsiz Yarınlar İçin Çözüm Önerileri, https://idealsosyalhizmet.com/engellibireylerin-toplumsal-hayatta-yasadiklari-zorluklar-ve-engelsiz-yarinlar-icin-cozum-onerileri/

Özbayram, G., G, (2018), Doğal Afetler Ve Yerel Topluluk Liderleri: Balıkesir Örnek Olay İncelemesi, T.C. Balıkesir Üniversitesi Sosyal Bilimler Enstitüsü Sosyoloji Anabilim Dalı, Y. Lisans Tezi,

Karakuş, U.,\& Önger, S. (2017). 8. Sınıf Öğrencilerinin Doğal Afet ve Afet Eğitimi Kavramını Anlama Düzeyleri. Journal of History Culture and Art Research, 6(6), 482-491. doi:http://dx.doi.org/10.7596/taksad.v6i6.1247

Yıldırım, A. \& Şimşek, H. (2006). Sosyal Bilimlerde Nitel Araştırma Yöntemleri. Ankara: Seçkin

Yumuşak, M., (2014), Engelli Bireylerin Ve Ailelerinin Toplumsal Hayatta Yaşadıkları Zorluklar Araştırma Raporu, ISBN: 978-605-125-909-3

URL-1 http://www.ct.gov/ctcdd/lib/ctcdd/Guide_final.pdf

URL-2 https://www.phe.gov/Preparedness/planning/abc/Pages/shelterinplace.aspx

URL-3 https://www.ready.gov/individuals-access-functional-needs

URL-4 http://www.disastersrus.org/MyDisasters/disability/disability_preparedness.htm 